\title{
CFD ANALYSIS OF MIXED FLOW IMPELLER
}

\author{
Neelambika ${ }^{1}$, Veerbhadrappa ${ }^{2}$ \\ ${ }^{1}$ Asst. Prof. Mechanical Engg Dept. Govt. Polytechnic Kalagi \\ ${ }^{2}$ Asst. Prof. Mech. Engg Dept. BKIT Bhalki-585328
}

\begin{abstract}
Now a day's Computational Fluid dynamics (CFD) is playing a vital role in all the fields. To improve the efficiency of mixed flow pump, Computational Fluid Dynamics analysis is one of the advanced tools used in the industry. A detailed CFD analysis was done to predict the flow pattern inside the impeller which is an active pump component. From the results of CFD analysis, the velocity and pressure in the outlet of the impeller is predicted. CFD analyses are done using Ansys software. These outlet flow conditions are used to calculate the efficiency of the impeller. The calculated value of efficiency from the empirical relations is 55\%. The optimum inlet and outlet vane angles are calculated for the existing impeller by using the empirical relations. The CAD models of the mixed flow impeller with optimum inlet and outlet angles are modeled using CAD modeling software Catia-V5R19. To find the relationship between the vane angles and the impeller performance the optimum vane angle is achieved step by step. Three CAD models are modeled with the vane angles between existing and optimum values. These models are analyzed individually to find the performance of the impeller. In the first case, outlet angle is increased by $5^{\circ}$. From the outlet flow conditions, obtained from the CFD analysis, it is evident that the reduced outlet recirculation and flow separation cause the improved efficiency. By changing the outlet angle the efficiency of the impeller is improved to 59\%. In the second case inlet angle is decreased by $10 \%$. The efficiency of the impeller in this case is $61 \%$. From this analysis it is understood that the changes in the inlet vane angle did not change the efficiency of the impeller as much as the changes in outlet angle. From the CFD analysis the efficiency of the impeller with optimum vane angles is calculated as $65 \%$. Thus, efficiency of the mixed flow impeller is improved by $18.18 \%$ by changing the inlet and outlet vane angles.
\end{abstract}

\section{INTRODUCTION}

A wide variety of centrifugal pump types have been constructed and used in many different applications in industry and other technical sectors. However, their design and performance prediction process is still a difficult task, mainly due to the great number of free geometric parameters, the effect of which cannot be directly evaluated. The significant cost and time of the trial-and-error process by constructing and testing physical prototypes reduces the profit margins of the pump manufacturers. For this reason CFD analysis is currently being used in the design and construction stage of various pump types.

The experimental way of pump test can give the actual value of head developed, power rating and efficiency. But the internal flow conditions cannot be predicted by the experimental results. From the CFD analysis software and advanced post processing tools the complex flow inside the impeller can be analyzed. The complex flow characteristics like inlet pre-swirl, flow separation and outlet recirculation cannot be visualized by the experimental way of pump test. But in the case of CFD analysis the above flow characters can be visualized clearly. Moreover design modification can be done easily and thus CFD analysis reduces the product development time and cost. Mixed flow pumps are widely used for water transportation or as cooling water pumps in power stations. Their operating range spans from full-load down to close to the shut-off head. In order to develop a reliable machine for this highly demanding operation, the behavior of the flow in the entire pump has to be predicted by a reliable computational method.

\section{PUMP CHARACTERISTICS}

\subsection{Cavitation}

Cavitation is a hydraulic phenomenon in which vapor bubbles form and suddenly collapse (implode) as they move through a pump impeller. Implosions occur on each of the vanes of the impeller causing excessive noise. The hydraulic effect on the pump is a significant reduction in performance. The mechanical effects can include shock waves and vibration which may result in damage to the impeller vanes, bearings, and seals.

\subsection{Vortexing}

A vortex can occur at the impeller and may extend to the surface of the liquid. If this occurs, air will be sucked into the pump. The effects can be similar to cavitation: reduced hydraulic efficiency and increased wear on the pump. Dicmas identifies three stages of vortexing 3 :

\subsection{Net Positive Suction Head Required}

Net positive suction head required (NPSHR) is the head above vapor pressure head required to ensure that cavitation does not occur at the impeller. The value is specific to each pump inlet 
design. It is independent of the suction piping system. The NPSHR is determined by bench scale tests of geometrically similar pumps operating at a constant speed and discharge with varying suction heads. The development of cavitation is usually indicated by approximately a 3\% drop in the head developed at the suction inlet valve. The NPSHR is specified by the manufacturer.

\subsection{Specific Speed}

Specific speed, $N_{s}$, is often quoted as a dimensionless design index for pump impellers. However, strictly speaking, it has dimensions that are in terms of:

$$
\left[\mathrm{L}^{0.75} \mathrm{~T}^{-0.5}\right] \times \text { revolutions per minute }
$$

Where $\mathrm{L}$ represents units of length, and $\mathrm{T}$ represents units of time.

Specific speed is used to identify an upper limit on the shaft speed for any particular combination of total head, flow, and suction conditions. The specific speed is determined using the following equation:

$$
N_{s}=C \frac{N Q^{0.5}}{H^{0.75}}
$$

$$
\begin{array}{llll}
N & = & \text { pump speed, rpm } & \\
Q & = & \text { pump capacity at Best } & \text { Efficiency } \\
(\mathrm{BEP}), \mathrm{m}^{3} / \mathrm{hr} & (\mathrm{gpm}) \\
H & = & \text { pump head at BEP }, \mathrm{m}(\mathrm{ft}) \\
C & = & \text { unit factor }=0.861 *(1)
\end{array}
$$

* For consistency with US manufacturers' pump data, a unit factor for metric units is given to result in a consistent value that is really in English units. The designer should verify the derivation and manufacturer's use of specific speed.

By applying pump affinity laws, a pump designer can predict the change in performance of a pump in response to changing speed. Discussion of affinity laws is beyond the scope of this manual. For a discussion, refer to a text such as Pump Performance Characteristics and Applications. ${ }^{4}$

\subsection{Suction Specific Speed}

Suction Specific Speed, $N_{s s}$, is a dimensionless index that is both representative of the geometry of the suction side of the impeller, and is used to determine the form and proportions of the impeller. The index can be used to select a pump maximum speed that will likely yield the smallest size of pump for the design conditions. It is determined using the following equation:

$$
N_{s s}=C \frac{N Q^{0.5}}{N P S H R^{0.75}}
$$

$N P S H R=$ net positive suction head required, $\mathrm{m}(\mathrm{ft})$

$N_{s s}=$ suction specific speed, $\mathrm{rpm}$

$N=$ pump speed, rpm

$Q=$ pump capacity at Best Efficiency Point (BEP), $\mathrm{m}^{3} / \mathrm{hr}$ (gpm)

$C=$ unit factor $=0.861 *(1)$

Selection of Impeller Type

Table 1.1 indicates the ranges of specific speed over various impellers that are recommended for use.

Table 1.1. Specific speed range for impellers

\begin{tabular}{|l|c|c|}
\multirow{2}{*}{\multicolumn{1}{|c|}{ Impeller Type }} & \multicolumn{2}{c|}{ Specific Speed } \\
\cline { 2 - 3 } & Upper & Lower \\
\hline \hline Axial Flow & 20,000 & 8,500 \\
\hline Mixed Flow (open) & 10,000 & 5,000 \\
\hline Mixed Flow (closed) & 6,200 & 4,000 \\
\hline Centrifugal & 4,100 & 2,500 \\
\hline
\end{tabular}

\subsection{Pump Performance}

Pump performance is measured as the variation in pumping capacity with respect to total dynamic head. Pump performance is a function of the following pump characteristics: pump type, pump size, impeller size, and speed.

Pump performance can be shown either as a single line curve for one impeller diameter or as multiple curves for the performance of several impeller diameters in one casing. Figure 1.3 shows a typical single pump performance curve.

The point at which maximum efficiency is achieved is represented by the best efficiency point, BEP, as shown in Figure 1.4.

In this work, the mixed flow pump detailed geometric feature of the impeller is studied and parameterization of impeller geometry is done. Parameterization is done by reducing number of controlling geometric variables, facilitating the investigation of their individual or combined effects on the flow and the impeller performance 


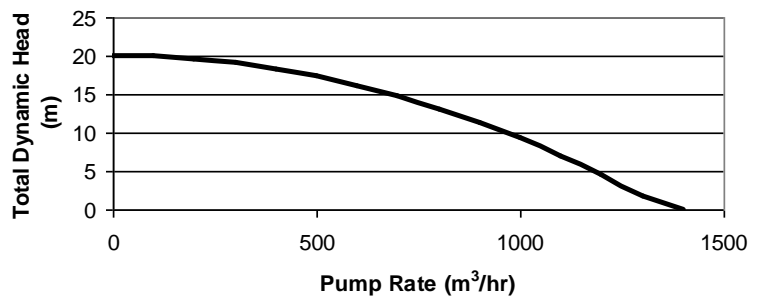

Fig.2.1: Typical pump performance curve

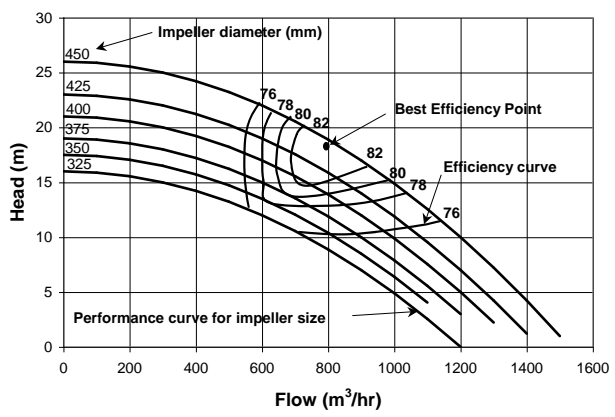

Fig.2.2: Simplified manufacturer's pump performance curves

The specification of the pump is given in the Table 2.2. Typical submersible pump consists of impeller, diffuser, riser, discharge adapter, intermediate bowl and shaft is shown in Fig.1.7The performance of a pump depends on active pump components. The active pump components of a mixed flow pump are mixed flow impeller and guide vanes. These parts are important while analyzing a pump because mechanical energy (rotation) is transferred into fluid energy (pressure, velocity) by the active pump components. The geometry of a mixed flow pump impeller is highly complex in nature. The mixed flow geometry consists of several features of which the following geometric features are important as they have direct effect on overall pump performance.

\begin{tabular}{|l|l|}
\hline \multicolumn{2}{|c|}{ Table 2.2: Specification of the pump } \\
\hline Bore size & $152.4 \mathrm{~mm}$ \\
\hline Capacity & $40 \mathrm{~m} 3 / \mathrm{hr}$ \\
\hline Number of stages & 6 \\
\hline \multicolumn{1}{|c|}{ Head } & $28 \mathrm{~m}$ per stage \\
\hline Flow type & Mixed flow \\
\hline
\end{tabular}

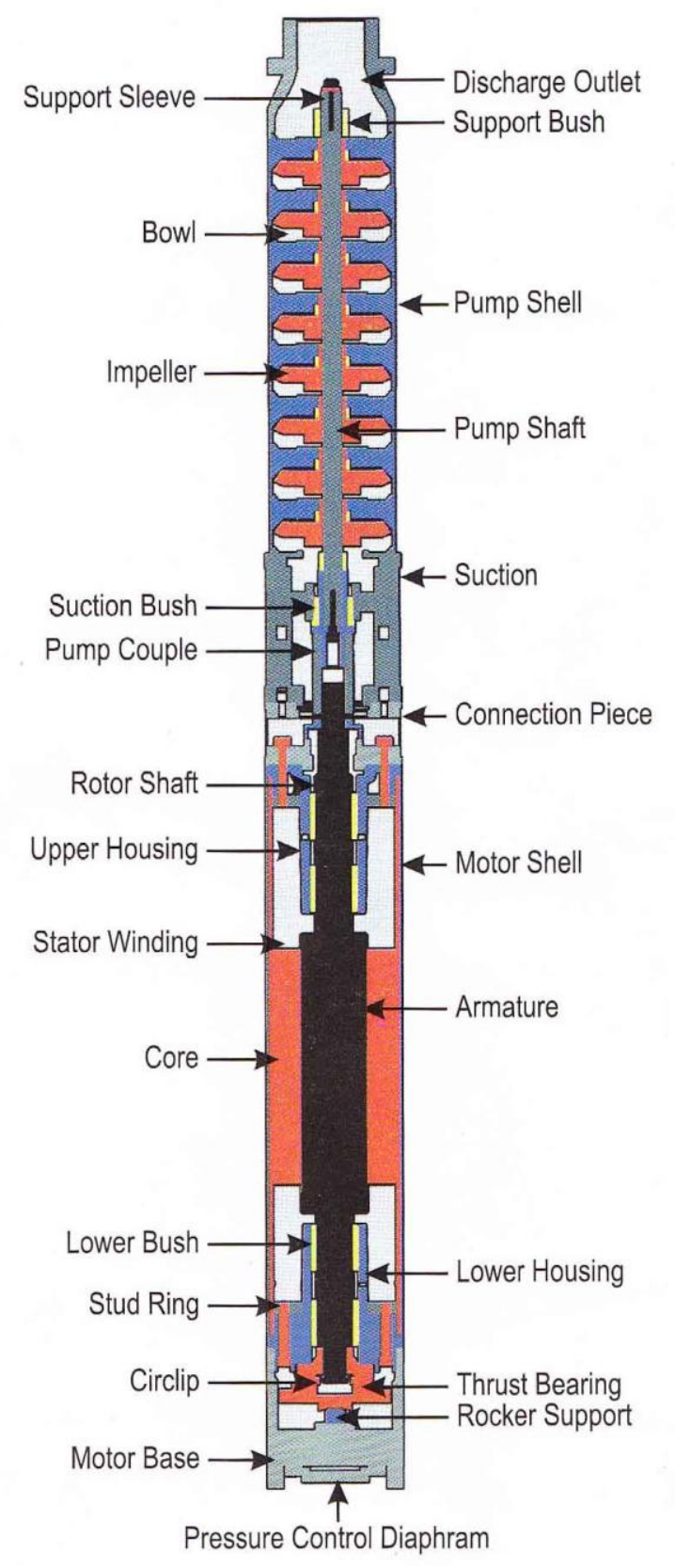

Fig.2.3: Mixed flow pump

\section{CFD ANALYSIS OF MIXED FLOW PUMP}

A thorough knowledge of all significant inviscid effects (blade blockage, flow turning, finite hub/tip ratio, etc.) and viscous effects (boundary-layer growth, energy dissipation, etc.) is essential in the accurate prediction of the flow in all turbo machinery. Relevant to this, the availability of computer with large storage capacities and fast computation times greatly enhance the possibility of numerically solving the complete equations of motion. It is widely accepted that the incompressible time-averaged Navier-Stokes equation 
together with the continuity equation comprise a closed set of equations, and which should be supplemented by appropriate boundary and initial conditions to form a complete description of the fluid velocity $\mathrm{u}(\mathrm{x}, \mathrm{t}) \mathrm{r}$ and pressure field in flow pumps.

\subsection{Geometric Modeling Pump}

\begin{tabular}{|l|l|}
\hline \multicolumn{2}{|c|}{ Table.3.1: Blade Impeller Parameter } \\
\hline Impeller inlet (Di) & $75 \mathrm{~mm}$ \\
\hline Impeller outlet (Do) & $105 \mathrm{~mm}$ \\
\hline Blades number & 6 \\
\hline Inlet angle( $\alpha$ ) & $55^{0}$ \\
\hline Outlet angle $(\beta)$ & $75^{0}$ \\
\hline Blade thickness (t) & $1.25 \mathrm{~mm}$ \\
\hline Blade inlet height (Li) & $21 \mathrm{~mm}$ \\
\hline Blade outlet height (Lo) & $16 \mathrm{~m}$ \\
\hline
\end{tabular}

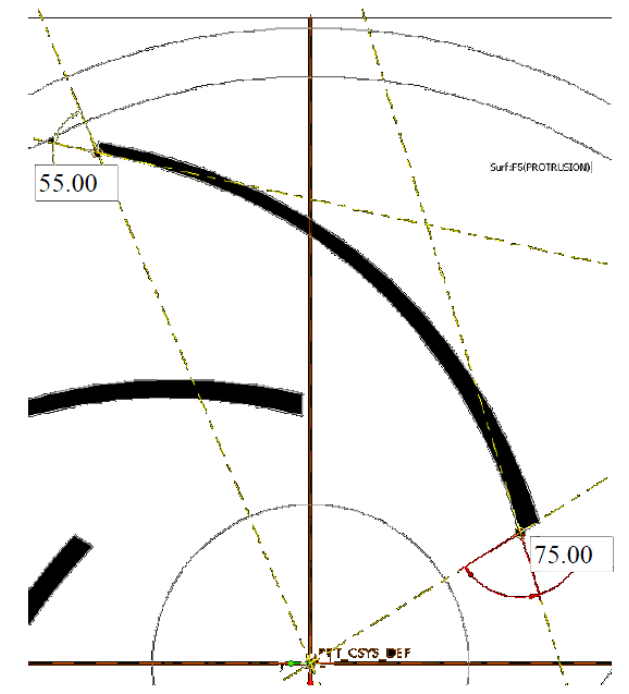

Fig 3.1: Existing Impeller vane dimensions

In RANS simulations, the choice of mesh type is of critical importance. In this study, the widely used structured bodyfitted curvilinear meshes are chosen rather than unstructured tetrahedral meshes. Body-fitted structured meshes are well suited for viscous flow because they can be easily compressed near all solid surfaces. Using a multi block approach, they are also convenient for discretizing the flow passages in turbomachinery flows with rather straightforward geometries, which includes blade tip clearances and relative motion.
The grid used for the present study is shown in Figure 3.6 and 3.7 with the $3 \mathrm{D}$ view and blade-to-blade view. The grid for the used for this study is impeller 0.3 millions.

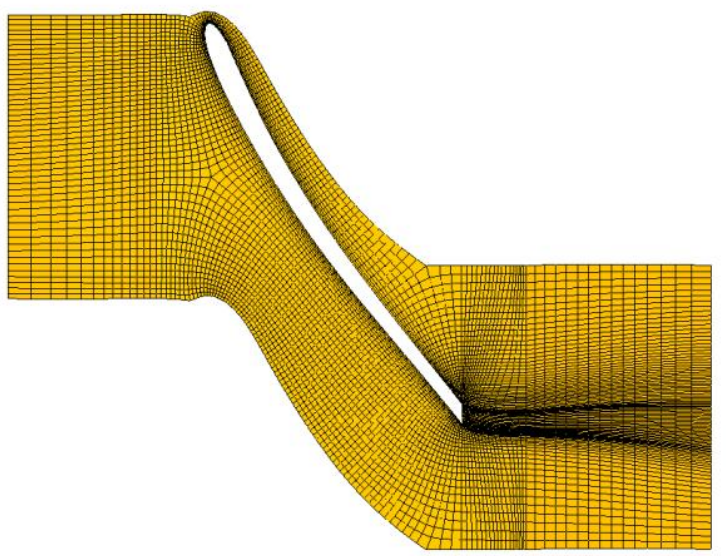

Fig.3.2: Blade to Blade View of Mixed Impeller Pump

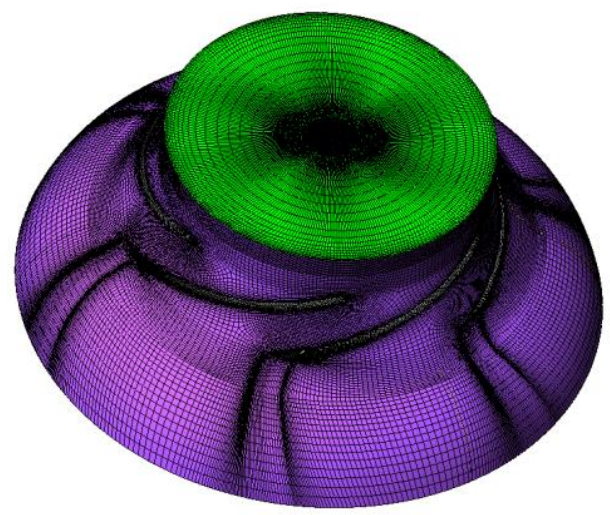

Fig. 3.3: CFD Meshing of Mixed Impeller Pump

\section{RESULTS AND DISCUSSIONS}

\subsection{Inlet angle $75^{\circ}$ and outlet Angle $55^{\circ}$}

\section{Flow distribution in impeller at different span}

The pressure increases gradually along stream wise direction within impeller passage and has higher pressure in pressure side than suction side of the impeller blade. However, the pressure developed inside the impeller is not so uniform. The isobar lines are not all perpendicular to the pressure side of the blade inside the impeller passage; this indicated that there could be a flow separation because of the pressure gradient effect. The fig 4.1 shows the pressure distribution within the impeller at three different 50 percent spans 




Fig. 4.1: Pressure distribution at 50\% span

Velocity also increases gradually along streamwise direction within the impeller passage.As the flow enters the impeller eye, it is diverted to the blade-to-blade passage. The flow at the entrance is not shockless because of the unsteady flow entering the impellerpassage. The separation of flow can be seen at the blade leading edge. Since, the flow atthe inlet of impeller is not tangential to the blade, the flow along the blade is not uniformand hence the separation of flow takes place along the surface of blade. Here it can beseen that flow separation is taking place on both side of the blade, ie, pressure and suction side as shown in fig 4.2

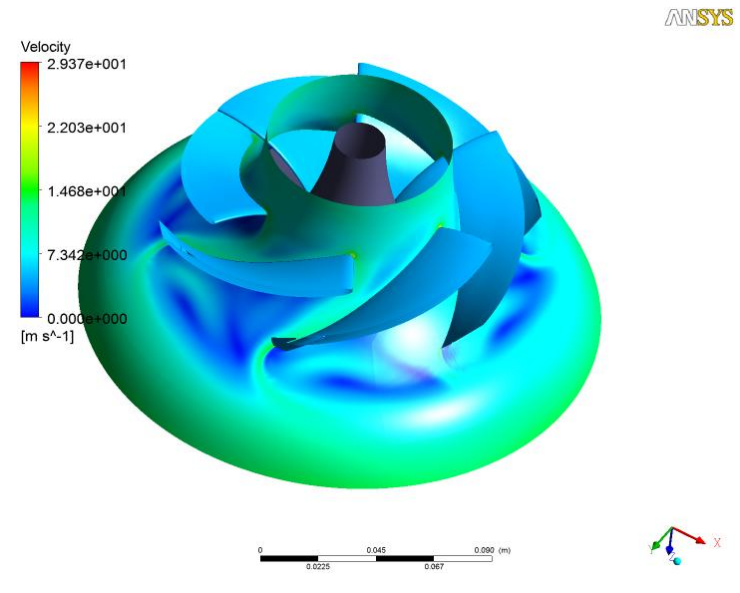

Fig. 4.2: Velocity distribution at 50\% span

\subsubsection{Pressure and Velocity between Impeller Blades}

The distribution of total pressure between the blades of the impeller is shown in the fig [4.3]. The lowest total pressure appears at the inlet of the impeller suction side. This is the position where cavitation often appears in the centrifugal pump. The highest total pressure occurs at the outlet of impeller, where the kinetic energy of flow reaches maximum.
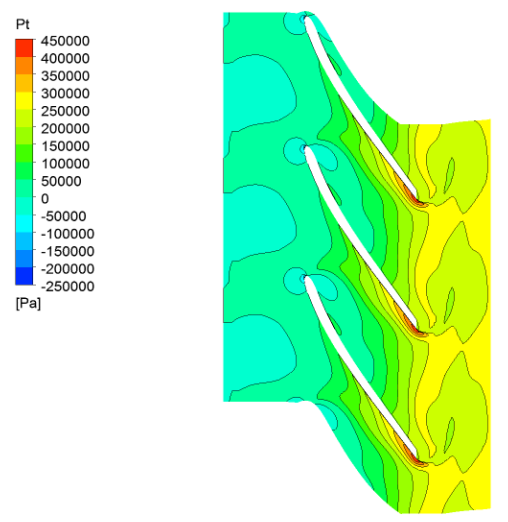

aNSYS

Fig. 4.3: Contour of $\mathrm{Pt}$ (Total Pressure) at 50\% Span

The fig [4.4] shows the static pressure distribution at the span of 50 between the blades of the impeller. It is observed that the static pressure inside the impeller blades is asymmetry distributed. The minimum static pressure area appears at the back of the impeller blade ie suction side, at the inlet.
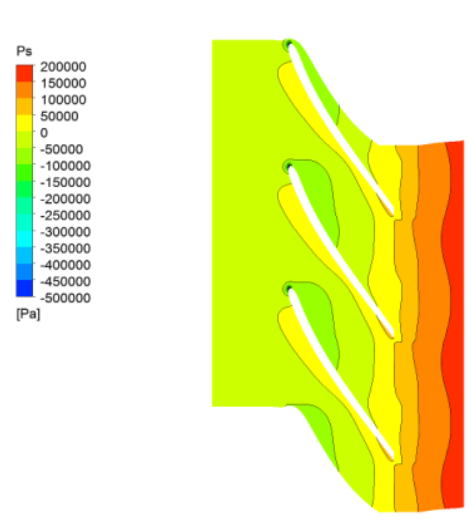

ansys

Fig. 4.4: Contour of Ps (Static Pressure) at 50\% Span

The fig [4.5] shows the relative velocity distribution at 50 span between two blades of the impeller. The rising flow speed of the fluid from inlet to outlet reaches maximum at the impeller blade outlet. From the pressure distribution plot, pressure gradient changes gradually from inlet radius to outlet radius for each impeller. In order to transmit power to the liquid, pressure on the leading or pressure side of the vane should be higher than pressure on the suction side of the vane. 

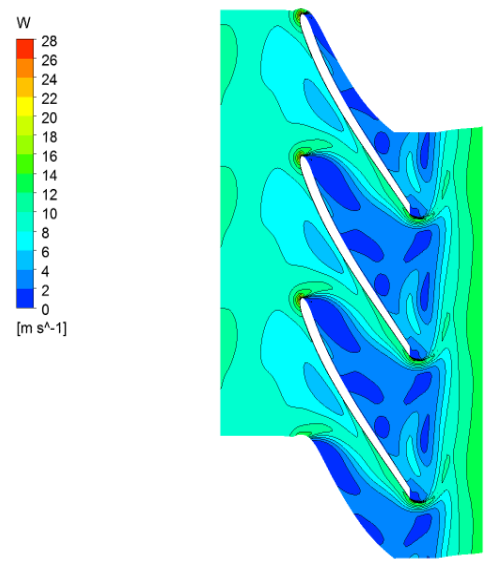

ansiss

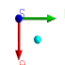

Fig. 4.5: Contour of Width of the element at 50\% Span

4.1. Fig. 4.6: Contour of Width element at Blade trailing edge

Fig [4.13] shows the velocity streamlines at the trailing edge which shows that how the flow leaves the blades of the impeller.

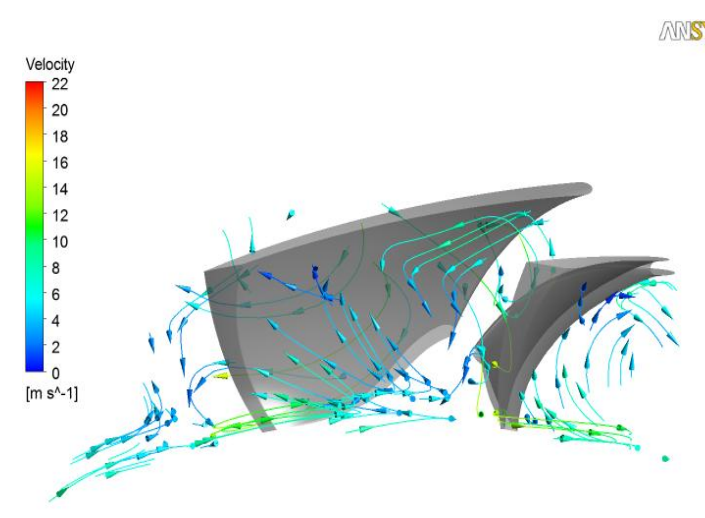

Fig.4.7: Velocity Streamlines at Blade trailing edge

\subsubsection{Blade Loading at Pressure and Suction Side}

The blade loading of pressure and suction side are drawn at three different locations on the blade at the span of 20,50 and 80 from hub towards the shroud. The pressure loading on the impeller blade is shown in fig [4.14]. Pressure load on the impeller blade is plot along the stream wise direction. The pressure difference on the pressure and suction sides of the blade suggests that the flow inside the impeller experiences the shearing effects due to the pressure difference on blade-toblade passage wall.
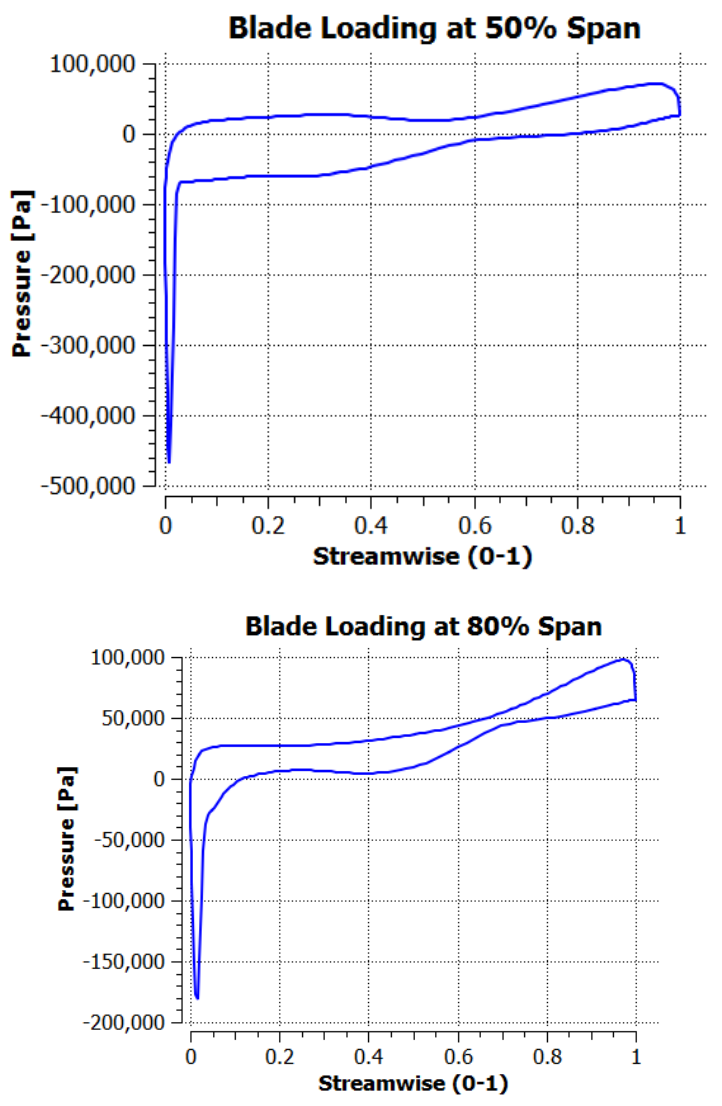

Fig.4.8: Blade loading at 20, 50 and 80 span

\subsubsection{Stream Wise Plots}

The effects of flow rate on the pressure inside the impeller passage along the stream wise direction are shown in Fig [4.15], which shows the flow rate effects on the pressure distribution on the impeller blade. The pressure for the minimum flow rate is found maximum at the outlet of the impeller and vice versa. Similarly relative velocity is shown in 4.16.

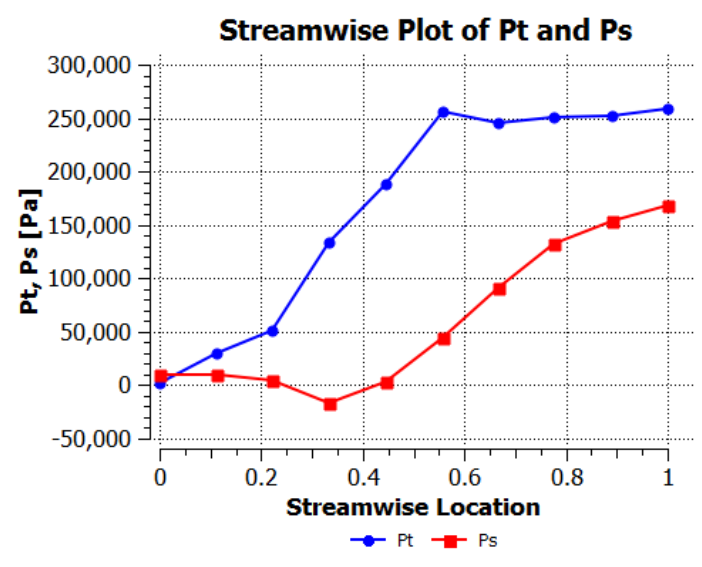

Fig. 4.9: Stream Wise plots Pressure 


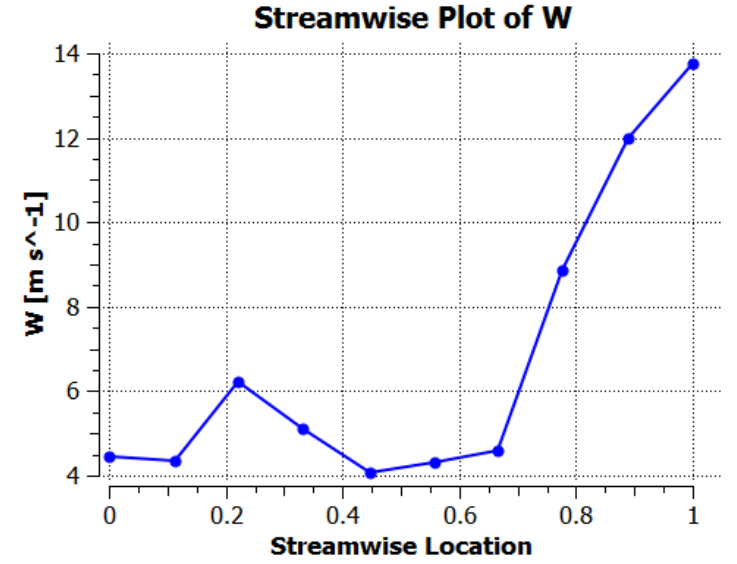

Fig. 4.10: Stream Wise plots Relative velocity

\section{CONCLUSIONS}

Based on the CFD analysis of the mixed flow impeller, the following conclusions are made. The best efficiency point of the pump is found to be $11 \mathrm{lps}$. The existing impeller, the head and efficiency are found out to be $19.24 \mathrm{~m}$ and $55 \%$ respectively. The impeller 1 , the percentage increase in the head and efficiency are $3.22 \%$ and $7.27 \%$ respectively. The impeller 2, the percentage increase in the head and efficiency are $10.29 \%$ and $10.91 \%$ respectively. The impeller 3, the percentage increase in the head and efficiency are $13.66 \%$ and $18.18 \%$ respectively. Based on the above, it is concluded that impeller 3 gives better performance. Thus CFD analysis is an effective tool to analyze quickly and inexpensively the effect of design and operating parameter of pump. By properly designing pump impeller, the efficiency of pump can be improved.

\section{REFERENCES}

[1] Lazarkiewicz, S. and Troskolanski, A. T. (1965) Impeller Pumps, Pergamon Press Ltd., Oxford.

[2] Goto, A. (1995) "Numerical and Experimental Study of 3-D Flow Fields within a Diffuser Pump Stage at OffDesign Condition," ASME Fluids 95, FED-Vol.227, pp. 1-9.

[3] 11. CFX User Manual Version 5.6 (2003) CFX Ltd., United Kingdom. 12. Muggli, F. A., Holbein, P. and Dupont, P., (2002) "CFD Calculation of aMixed Flow Pump Characteristics from Shutoff to Maximum Flow" ASME Journal of Fluids Engineering., Vol. 124, pp. 798-802. 94

[4] 13. CFdesign User's Guide Version 7.0 (2004) Blue Ridge Numerics, Inc., Charlottesville.

[5] 14. Hirsch, Ch. (1994) "CFD Methodology and Validation for Turbomachinery Flows", Turbomachinery Design Using CFD-AGARD Lecture Series 195,Specialised Printing Services, Essex, pp 4-7.
[6]

15. Majidi, K., (2005) “ Numerical Study of Unsteady Flow in a Centrifugal Pump" ASME Journal of Turbomachinery., Vol. 127, pp. 363-371. 